\title{
Réquiem aos bens públicos e a imprescritibilidade das ações de ressarcimento em matéria de improbidade administrativa: anotações críticas
}

rdai.com.br/index.php/rdai/article/view/425

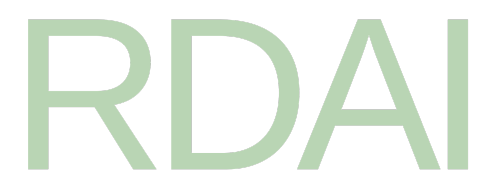

\section{Autores}

Rogério Gesta Leal Leal Universidade de Santa Cruz do Sul (Santa Cruz do Sul, Rio Grande do Sul, Brasil)

\section{DOI:}

https://doi.org/10.48143/rdai.19.rgl

\section{Palavras-chave:}

Improbidade administrativa, Prescrição, Dano ao erário, Ato culposo, Ação de ressarcimento

\section{Resumo}

O presente trabalho tem, como escopo, uma abordagem crítica da jurisprudência do Supremo Tribunal Federal quanto ao tratamento à prescritibilidade das ações de ressarcimento por danos provocados ao Estado, sobretudo com repercussões negativas ao Erário, gerados por condutas tipificadas como atos de improbidade administrativa, com especial atenção ao resultado do julgamento do RE 852.475, pelo qual se reduziu a imprescritibilidade das ações de ressarcimento às hipóteses de dano gerado por atos dolosos daquela natureza. Enfrentam-se, assim, os fundamentos basilares do instituto, bem como o tratamento positivado no ordenamento quanto à proteção dos bens jurídicos públicos tutelados.

\section{Biografia do Autor}

\section{Rogério Gesta Leal Leal, Universidade de Santa Cruz do Sul (Santa Cruz do Sul, Rio Grande do Sul, Brasil)}

Professor titular da Universidade de Santa Cruz do Sul (Rio Grande do Sul, Brasil). Doutorado em direito pela Universidade Federal de Santa Catarina. Mestrado em Desenvolvimento Regional e graduação em Direito pela UNISC. Leciona na Fundação Escola Superior do Ministério Público-RS e Coordena o NPJ da Escola Nacional de 
Formação e Aperfeiçoamento dos Magistrados Brasileiros. Membro da Rede de Direitos Fundamentais do CNJ. Conselheiro Científico do Observatório da Justiça Brasileira. Coordenador Executivo do Comitê de Gestão da Rede dos Observatórios do Direito à Verdade, à Memória e à Justiça das Universidades Brasileiras. Membro da Comissão de Altos Estudos do Centro de Referência Memórias Reveladas.

(D) 0000-0002-2005-241X | gestaleal@gmail.com

\section{Referências}

ALESSI, Renato. Instituciones de derecho administrativo. Buenos Aires: Casa Editorial, 1990.

BACIGALUPO, Silvina. Delitos de infração de dever e acessoriedade no direito penal. In: OLIVEIRA, William Terra de; LEITE NETO, Pedro Ferreira; ESSADO, Tiago Cintra e SAAD-DINIZ, Eduardo (Org.). Direito penal econômico: estudos em homenagem aos 75 anos do professor Klaus Tiedemann. São Paulo: LiberArs, 2013.

BANDEIRA DE MELLO, Celso Antônio. Elementos de direito administrativo. São Paulo: Malheiros, 2017.

BATTAGLINI, Cosi Orsi. Attività vincolata e situazioni soggettive. Padova: Daltricce, 2004.

BIELSA, Rafael. Derecho administrativo. Buenos Aires: La Ley, 1975.

BITENCOURT NETO, Eurico. Improbidade administrativa e violação de princípios. Belo Horizonte: Del Rey, 2005.

BONNARD, Roger. Précis de Droit Administratif. Paris: Libraire du Recueil Sirey, 1993.

BRANDÃO, Antônio José. Moralidade administrativa. Revista de Direito Administrativo, Rio de Janeiro, v. 25, jul.-set. 1951.

BUENO, Eduardo. A coroa, a cruz e a espada: lei, ordem e corrupção no Brasil colônia. Rio de Janeiro: Objetiva, 2006.

CARVALHO FILHO, José dos Santos. Manual de direito administrativo. Rio de Janeiro: Lumen Juris, 2006.

CAVALCANTI, Themístocles Brandão. Tratado de direito administrativo. São Paulo: Freitas Bastos, 1986.

DAL BOSCO, Maria Goretti. Responsabilidade do agente público por ato de improbidade. Rio de Janeiro: Lumen Juris, 2004.

DECOMAIN, Pedro Roberto. Improbidade administrativa. São Paulo: Dialética, 2007.

DI PIETRO, Maria Sylvia Zanella. Discricionariedade administrativa na Constituição de 1988. São Paulo: Atlas, 1991. 
DI PIETRO, Maria Sylvia Zanella. Direito administrativo. São Paulo: Atlas, 2005.

DWORKIN, Ronald. Justice for Hedgehogs. Cambridge: Harvard University Press, 2011.

FAZZIO JUNIOR, Waldo; PAZZAGLINI FILHO, Marino; ROSA, Márcio Fernandes Elias. Improbidade administrativa. São Paulo: Atlas, 1999.

FRANCO SOBRINHO, Manoel de Oliveira. O princípio constitucional da moralidade administrativa. Curitiba: Genesis Editora, 1993.

FIGUEIREDO, Lucia Valle. Curso de direito administrativo. São Paulo: Malheiros, 1999. FIGUEIREDO, Marcelo. O controle da moralidade na Constituição. São Paulo: Malheiros, 1999.

FORNACIARI JUNIOR, Clito. Prescrição das ações de ressarcimento de danos causados por ato de improbidade administrativa. Revista de Informação Legislativa, Brasília, v. 165, p. 34-35, 2005 .

GABARDO, Emerson. A nova decisão do STF sobre a imprescritibilidade do ressarcimento ao erário por ato de improbidade.Direito do Estado, n. 409, edição de 11.08.2018. Disponível em: [www.direitodoestado.com.br/colunistas/emersongabardo/a-nova-decisao-do-stf-sobre-a-imprescritibilidade-do-ressarcimento-ao-erariopor-ato-de-improbidade]. Acesso em: 27.10.2020.

GARCIA, Emerson; ALVES, Rogério Pacheco. Improbidade administrativa. Rio de Janeiro: Lumen Juris, 2002.

GARCIA, Emerson. Improbidade administrativa: configuração e reparação do dano moral. Revista da EMERJ, v. 12, n. 48, 2009.

GOMES, Emerson C. S. Responsabilidade financeira: uma teoria sobre a responsabilidade no âmbito dos tribunais de contas. Porto Alegre: Núria Fabris, 2012.

GRECO, Guido. Argomenti di Diritto Amministrativo. Milano: Giuffrè, 2002.

GRONDIN, Jean. Introdução à hermenêutica filosófica. São Leopoldo: Unisinos, 1999.

HAURIOU, Maurice. Précis de Droit Administratif et de Droit Public. Paris: Recueil Sirey, 1920.

KINDHÄUSER, Urs. Derecho penal de la culpabilidad y conducta peligrosa. Bogotá: Universidad Externado, 1996.

LEAL, Rogerio Gesta. Estado, administração pública e sociedade: novos paradigmas. Porto Alegre: Livraria do Advogado, 2006.

LEAL, Rogerio Gesta. Patologias corruptivas nas relações entre estado, administração pública e sociedade: causas, consequências e tratamentos. Santa Cruz do Sul: Edunisc, 2013. 
LIMA, Ruy Cirne. Princípios de direito administrativo. Porto Alegre: Globo, 1984.

MORIN, Gastón. La revolte des fait contre le Code. Paris: FDL, 1990.

OSÓRIO, Fábio Medina. Teoria da improbidade administrativa: má gestão pública, corrupção e ineficiência. São Paulo: Ed. RT, 2007.

PAOLO, Mauro. Corruption and Growth. Quarterly Journal of Economics, v. 110, p. 681712, ago. 1995 .

PAZZAGLINI FILHO, Marino; ROSA, Márcio Fernando Elias; FAZZIO JR., Waldo. Júnior Improbidade administrativa: aspectos jurídicos na defesa do patrimônio público. São Paulo: Atlas, 1999.

PRADO, Francisco Octávio de Almeida. Improbidade administrativa. São Paulo: Malheiros Editores, 2001.

RIPERT, George. La régle morale dans les obligations civiles. Paris: Dalloz, 1984.

ROTHEBURG, Walter Claudius. Ação de improbidade administrativa: aspectos de relevo. In: SAMPAIO, José Adércio Leite et al. (Org.). Improbidade administrativa: comemoração pelos 10 anos da Lei 8.429/92 (LGL199219). Belo Horizonte: Del Rey, 2002.

SILVA, José Afonso da. Curso de direito constitucional positivo. São Paulo: Malheiros, 2005 .

TOURINHO, Rita Andréa Rehem Almeida. A prescrição e a Lei de Improbidade Administrativa. Disponível em: [https://jus.com.br/artigos/5054/a-prescricao-e-a-lei-deimprobidade-administrativa] Acesso em: 03.11.2020.

\section{Publicado}

2021-12-15

\section{Como Citar}

LEAL, R. G. L. Réquiem aos bens públicos e a imprescritibilidade das ações de ressarcimento em matéria de improbidade administrativa: anotações críticas: Requiem to public goods and the imprescriptibility of actions for compensation in matters of administrative misconduct: critical notes. Revista de Direito Administrativo e Infraestrutura | RDAI, São Paulo: Thomson Reuters - Livraria RT, v. 5, n. 19, p. 101131, 2021. DOI: 10.48143/rdai.19.rgl. Disponível em:

https://rdai.com.br/index.php/rdai/article/view/425. Acesso em: 7 fev. 2022.

\section{Edição}

V. 5…19-(2021). 


\section{Seção}

Direito Administrativo: Direito administrativo sancionador

\section{Licença}

\section{(c) $(1) \Theta(9$}

Este trabalho está licenciado sob uma licença Creative Commons Attribution-

NonCommercial-NoDerivatives 4.0 International License.

(CC BY-NC-ND).

Este é um resumo (e não um substituto) da licença

Regras para publicação

Direitrizes Editoriais

Direitos e Deveres

Errata e Retratação

Preservação e Plagiarismo

Revisão e Avaliaçãa 
